\title{
Produtividade de grãos de milho, produção de matéria seca e acúmulo de nitrogênio, fósforo e potássio na rotação aveia preta/milho/nabo forrageiro com aplicação de dejeto líquido de suínos
}

\author{
Corn grain yield, dry matter and accumulation of nitrogen, phosphorus and potassium \\ in a black oat/corn/ oilseed radish rotation after application of pig slurry.
}

\author{
Carlos Alberto Ceretta ${ }^{1}$ Claudir José Basso ${ }^{2}$ Paulo Sérgio Pavinato ${ }^{3}$ \\ Eder Efrain Trentin ${ }^{4}$ Eduardo Girotto ${ }^{4}$
}

\section{RESUMO}

Os dejetos líquidos de suínos são largamente utilizados em cultivos comerciais ou de plantas de cobertura de solo e a definição da quantidade a ser utilizada depende da eficiência de uso dos nutrientes pelas plantas. O trabalho teve por objetivo avaliar a eficiência de uso de nutrientes aplicados via dejeto líquido de suínos à nutrição de plantas, considerando o acúmulo de nutrientes nas plantas, em uma rotação de culturas representativa de regiões suinícolas. Foram aplicados 0, 20, 40 e $80 \mathrm{~m}^{3} \mathrm{ha}^{-1}$ de dejeto líquido de suínos antes da semeadura de cada espécie na rotação. A maior eficiência técnica para a produtividade de grãos de milho $e$ para produção de matéria seca de aveia preta ocorreu com doses muito altas de dejeto líquido de suínos, ou seja, em torno de $85 \mathrm{~m}^{3} \mathrm{ha}^{-1}$, que somado ao incremento linear no acúmulo de $N$, P e K na maioria dos casos, evidencia que na tomada de decisão sobre doses de dejeto deve ser levado em consideração também aspectos operacionais, econômicos e ambientais. $O$ nabo forrageiro foi a cultura que se destacou na ciclagem dos nutrientes aplicados via dejeto líquido de suínos. Os porcentuais de recuperação aparente de nutrientes pelo milho, que foram na ordem $K>N>P$, mostram que devem ser tomadas medidas para a conservação do solo visando maior aproveitamento do efeito residual, diminuindo o potencial de perdas.

Palavras-chave: esterco, resíduos de animais, adubação orgânica.

\section{ABSTRACT}

Pig slurry is widely used as a nutrient source for crops or cover crops but the amount to be applied depends on the efficiency of use by plants. This work aimed at evaluating the efficiency of plants used in typical crop succession in Brazilian areas of pig production to accumulate nutrients from pig slurry application. Application of 0, 20, 40 and $80 \mathrm{~m}^{3} \mathrm{ha}^{-1}$ before seeding of each species was done. The most efficient dose for corn grain yield and dry matter production of black oat was estimated as $85 \mathrm{~m}^{3} \mathrm{ha}^{-1}$. This large amount and the linear increase in the accumulation of $N, P$ and $K$ suggest that its use may raise operational, economical and environmental issues. Oilseed radish was particularly efficient in nutrient cycling. The apparent percent recover of nutrients by corn $(K>N>P)$ indicated that conservation practices should be applied to avoid losses.

Key words: manure, animal waste, organic fertilizer.

\section{INTRODUÇÃO}

Na utilização de dejeto líquido de suínos, é preciso compatibilizar o seu necessário descarte com os interesses à nutrição de plantas e qualidade ambiental. Isso porque os nutrientes apresentam-se sob diferentes formas quanto a sua disponibilidade

\footnotetext{
${ }^{1}$ Departamento de Solos, Universidade Federal de Santa Maria (UFSM), 97105-900, Santa Maria, RS, Brasil. E-mail: ceretta@ccr.ufsm.br. Autor para correspondência.

${ }^{2}$ SLC Agrícola, Luiziânia, Goias, Brasil.

${ }^{3}$ Universidade Estadual Paulista, São Paulo, SP, Brasil.

${ }^{4}$ Curso de Agronomia, UFSM, Santa Maria, RS, Brasil.
} 
(SCHERER et, al., 1996), o que implica em adotar práticas para potencializar o seu uso. $\mathrm{O}$ fato dos dejetos de suínos possuírem nutrientes em quantidades desbalanceadas dificulta a utilização de referenciais para a recomendação de doses. Contudo, a utilização de $40 \mathrm{~m}^{3}$ ha $^{-1}$ de dejeto líquido de suínos proporcionou incremento médio de 22 sacas de milho $\mathrm{ha}^{-1}$, sendo equivalente a uma aplicação de $40 \mathrm{~kg} \mathrm{ha}^{-1}$ de $\mathrm{N}$ mineral na forma de uréia e isso motivou SCHERER et al. (1986) a citar essa dose como um referencial. Contudo, um estudo feito por SCHMITT (1995) mostra que na região de Videira-SC apenas $60 \%$ das propriedades que desenvolvem a atividade suinícola fazem uma distribuição economicamente viável desse resíduo.

A suinocultura é típica de pequena propriedade no Brasil e alguns estudos internacionais com doses de dejeto muito elevadas, como, por exemplo, de EVANS et al. (1977) que mostra incrementos na produtividade de grãos de milho com a aplicação de $636 \mathrm{mg} \mathrm{ha}^{-1}$ de dejeto de suínos (base úmida) nos Estados Unidos. Contudo, os autores não recomendam o uso repetido de doses tão elevadas, pois observaram a percolação de nitrato $\left(\mathrm{NO}_{3}^{-}\right)$além da zona explorada pelo sistema radicular do milho. Por outro lado, ao utilizarem apenas $30 \mathrm{mg} \mathrm{ha}^{-1} \mathrm{ano}^{-1}$ de dejeto líquido de suínos (180 a 200kg de $\mathrm{N} \mathrm{ha}^{-1}$ ) durante 5 anos no milho para silagem, FAUVEL \& MORVAN (1998) observaram que a produção de matéria seca com aplicação do dejeto foi superior em 12,5 e $33 \%$ às doses de 60 e $124 \mathrm{~kg}$ ha $^{-1}$ de $\mathrm{N}$ via fertilizante mineral, respectivamente. Para esses autores, é possível obter altos índices de produtividade de milho sem danos maiores ao ambiente pela contaminação da água por nitrato, mesmo com o uso anual do dejeto na mesma área, embora se deve considerar que essa observação foi feita a partir do seu trabalho com o uso de baixa dose anual de dejeto.

O trabalho teve por objetivo avaliar a eficiência de uso de nutrientes à nutrição de plantas, aplicados via dejeto líquido de suínos , em uma rotação de culturas representativa de regiões suinícolas, visando oferecer subsídios para o uso mais eficiente desse dejeto, evitando potencializar sua capacidade poluente.

\section{MATERIAL E MÉTODOS}

O trabalho foi desenvolvido de maio de 2000 a maio de 2002 na Universidade Federal de Santa Maria, RS, em Argissolo Vermelho distrófico arênico com as seguintes características ( 0 a $10 \mathrm{~cm}$ ): argila $240 \mathrm{~g} \mathrm{~kg}^{-1}$, pH (água 1:1) 4,7, M.O. 16g kg-1, P 15,0mg dm${ }^{-3}$,
K 96,0 $\mathrm{mg} \mathrm{dm}^{-3}$, Al, Ca e Mg 0,8, 2,7 e 1,1 $\mathrm{cmol}_{\mathrm{c}} \mathrm{dm}^{-3}$, respectivamente, e há oito anos sob plantio direto.

Foram conduzidos dois ciclos da rotação aveia preta/milho/nabo forrageiro utilizando-se 0,20 , 40 e $80 \mathrm{~m}^{3} \mathrm{ha}^{-1}$ de dejeto líquido de suínos aplicado antes da semeadura das culturas: aveia preta (Avena strigosa Schieb), milho (Zea mays) e nabo forrageiro (Raphanus sativus), totalizando três aplicações anuais. O delineamento foi de blocos ao acaso com quatro repetições e parcelas com $14 \mathrm{~m}^{2}$. Algumas características do dejeto utilizado antes da implantação de cada cultivo são mostradas na tabela 1 .

A semeadura da aveia preta foi a lanço com 108 e $100 \mathrm{~kg} \mathrm{ha}^{-1}$, no primeiro e segundo ano, respectivamente. No florescimento pleno, em uma área de $0,25 \mathrm{~m}^{2}$, coletou-se plantas para determinação da matéria seca e acúmulo de N, P e K e posteriormente feita a dessecação com herbicida. Nos dois anos e aproximadamente 20 dias após o manejo da aveia preta, foi realizada a semeadura do milho, híbrido 30F44. A produção de matéria seca e acúmulo de N, P e K na parte aérea do milho foram determinados no estádio de pleno florescimento coletando-se quatro plantas por parcela. A produtividade de grãos foi determinada em área útil de $6,3 \mathrm{~m}^{2}$ e a umidade corrigida para $13 \%$. Após a colheita do milho e um dia depois da aplicação do dejeto, foi realizada a semeadura do nabo forrageiro com 20 e $30 \mathrm{~kg} \mathrm{ha}^{-1}$ para o primeiro e segundo ano, respectivamente. No início do florescimento do nabo, foi efetuada a coleta de plantas para as avaliações em uma área de $0,25 \mathrm{~m}^{2}$. Após a secagem e determinação da matéria seca, foi feita a moagem e digestão, sendo o $\mathrm{N}$ total determinado em destilador de arraste de vapor semi-micro Kjeldhal (TEDESCO et al., 1995). Usando uma amostra da alíquota obtida na digestão, foram determinados os teores totais de $\mathrm{P}$ e $\mathrm{K}$ por fotocolorimetria e fotômetro de chama, respectivamente. Para a estimativa da recuperação aparente dos nutrientes pelas plantas de milho até o estádio de pleno florescimento, foi adotado o procedimento proposto por ZEBARTH et al. (1996), o qual não considera o efeito residual.

Em todos os parâmetros, efetuou-se a análise da variância a 5\% de probabilidade de erro, testando-se a interação entre as espécies da rotação e as doses de dejeto e nos dados quantitativos foi efetuado análise de regressão.

\section{RESULTADOS E DISCUSSÃO}

A utilização do dejeto líquido de suínos promoveu incremento na produção de matéria seca em todas as espécies da rotação. No primeiro ano e no 
Tabela 1 - Características do dejeto líquido de suínos aplicado antes da implantação de cada cultura da sucessão aveia preta/milho/nabo forrageiro nos dois anos e quantidades em $\mathrm{kg} \mathrm{ha}^{-1}$ de $\mathrm{N}, \mathrm{P}$ e K aplicadas com as doses de 20, 40 e $80 \mathrm{~m}^{3} \mathrm{ha}^{-1}$.

\begin{tabular}{|c|c|c|c|c|c|c|c|c|c|c|c|c|}
\hline \multirow{4}{*}{$\begin{array}{l}\text { Característica do } \\
\text { dejeto } \\
\mathrm{pH}\end{array}$} & \multicolumn{12}{|c|}{ Antes da implantação de cada cultivo } \\
\hline & \multicolumn{4}{|c|}{ Aveia preta } & \multicolumn{4}{|c|}{ Milho } & \multicolumn{4}{|c|}{ Nabo forrageiro } \\
\hline & \multicolumn{12}{|c|}{ Primeiro ano agrícola (2000/2001) } \\
\hline & & & 7,2 & & & & 6,6 & & & & 7,5 & \\
\hline \multirow[t]{2}{*}{ \% matéria seca } & & & 1,9 & & & & 9,9 & & & & 0,8 & \\
\hline & \multicolumn{12}{|c|}{ Aplicação - kg ha ${ }^{-1}$} \\
\hline Dose $-\mathrm{m}^{3} \mathrm{ha}^{-1}$ & $\%$ & 20 & 40 & 80 & $\%$ & 20 & 40 & 80 & $\%$ & 20 & 40 & 80 \\
\hline N-total ${ }^{(1)}$ & 0,11 & 22 & 44 & 88 & 0,75 & 151 & 301 & 602 & 0,14 & 28 & 56 & 112 \\
\hline Fósforo total ${ }^{(2)}$ & 2,40 & 9 & 18 & 36 & 2,1 & 42 & 84 & 168 & 4,10 & 3,4 & 6,8 & 13,6 \\
\hline \multirow[t]{2}{*}{ Potássio total } & 1,2 & 4,5 & 8,9 & 17,8 & 4,6 & 91,4 & 183 & 365 & 2,4 & 3,8 & 7,7 & 15,4 \\
\hline & \multicolumn{12}{|c|}{ Segundo ano agrícola (2001/2002) } \\
\hline $\mathrm{pH}$ & & & 6,8 & & & & 7,8 & & & & 8,2 & \\
\hline \% matéria seca & & & 1,1 & & & & 3,7 & & & & 1,2 & \\
\hline \multirow[t]{2}{*}{$\%$ N-total ${ }^{(2)}$} & & & 3,5 & & & & 2,7 & & & & 3,1 & \\
\hline & \multicolumn{12}{|c|}{ Aplicação - kg ha-1 } \\
\hline Dose $-m^{3} h a^{-1}$ & $\%$ & 20 & 40 & 80 & $\%$ & 20 & 40 & 80 & $\%$ & 20 & 40 & 80 \\
\hline N-total ${ }^{(1)}$ & 0,08 & 16 & 32 & 64 & 0,2 & 40 & 80 & 160 & 0,18 & 36 & 72 & 144 \\
\hline Fósforo total ${ }^{(2)}$ & 1,50 & 3,3 & 6,6 & 13,2 & 1,6 & 12 & 24 & 48 & 1,3 & 3,1 & 6,2 & 12,4 \\
\hline Potássio total & 1,3 & 2,9 & 5,8 & 11,6 & 2,1 & 15,5 & 31 & 62 & 1,7 & 4,1 & 8,2 & 16,3 \\
\hline
\end{tabular}

${ }^{(1)}$ Análise e cálculos em base úmida. ${ }^{(2)}$ Análise e cálculos em base seca

somatório da rotação aveia preta/milho/nabo forrageiro, os aumentos foram de 128, 223 e 331\% com as doses de 20, 40 e $80 \mathrm{~m}^{3} \mathrm{ha}^{-1}$, significando uma produção de matéria seca de 14,39, 20,42 e 27,26mg ha${ }^{1}$, respectivamente, contra $6,32 \mathrm{mg} \mathrm{ha}^{-1}$ na área sem o uso de dejeto (Figura 1). A máxima eficiência técnica para produção de matéria seca foi obtida com $86 \mathrm{~m}^{3}$ ha${ }^{1}$, ou seja, acima da dose máxima utilizada, embora se deve considerar que os incrementos foram menores a partir da dose de $40 \mathrm{~m}^{3} \mathrm{ha}^{-1}$ na aveia preta e milho no primeiro ano.

No segundo ano, os aumentos foram lineares na produção de matéria seca, atingindo 8,25 , 10,74 e $15,73 \mathrm{mg} \mathrm{ha}^{-1}$ com as doses de 20,40 e $80 \mathrm{~m}^{3}$ ha $^{-1}$, respectivamente, resultando em incrementos de 43,87 e $174 \%$, ou seja muito inferiores àqueles do primeiro ano. Observa-se que, em quatro das seis situações nos dois anos, as respostas às doses foram lineares e positivas, assemelhando-se ao que foi obtido por ZEBARTH et al. (1996) e ALMEIDA (2000) ao trabalharem com milho e utilizando doses de dejeto líquido de suínos. Contudo, como as produções foram semelhantes nos dois anos quando não foi aplicado dejeto (6,32 e 5,75 $\mathrm{mg} \mathrm{ha}^{-1}$, no primeiro e segundo ano, respectivamente), os menores porcentuais de acréscimo no segundo ano, provavelmente deve-se ao fato de que, no milho, no primeiro ano, foi aplicado um dejeto com alto teor de matéria seca (9,9\%) e, ao iniciar a rotação no segundo ano, havia um residual das três aplicações do ano anterior. Isso mostra a importância de conduzir trabalhos desta natureza por maiores períodos de tempo.

Na média da rotação aveia preta/milho/nabo forrageiro, no primeiro ano, para cada $\mathrm{m}^{3}$ de dejeto aplicado, houve uma produção de matéria seca de 403, 352 e $340 \mathrm{~kg} \mathrm{ha}^{-1}$ com as doses de 20, 40 e $80 \mathrm{~m}^{3} \mathrm{ha}^{-1}$, respectivamente. Isso mostra uma redução na eficiência nutricional do dejeto à medida que ocorre um aumento na dose aplicada o que também é detalhado por DURIGON et al. (2003) após trabalharem com aplicação de dejeto líquido de suínos em pastagem natural durante quatro anos. Contudo e curiosamente, no segundo ano, houve um incremento de $125 \mathrm{~kg} \mathrm{ha}^{-1}$ para cada $\mathrm{m}^{3}$ de dejeto aplicado, independente da dose e isso pode ter sido favorecido pelo fato de que, na média na rotação, a produção de matéria seca no segundo ano foi $44 \%$ inferior ao do primeiro ano.

O reflexo da maior produção de matéria seca, no primeiro ano, foi o alto acúmulo de N, o qual atingiu 119, 215 e 339\% em relação a testemunha para as doses de 20 , 40 e $80 \mathrm{~m}^{3}$ ha $^{-1}$ (Figura 2). É importante observar que esses porcentuais estão muito próximos dos obtidos para os incrementos na produção de matéria seca. Por outro lado, os acréscimos no acúmulo de $\mathrm{N}$ 


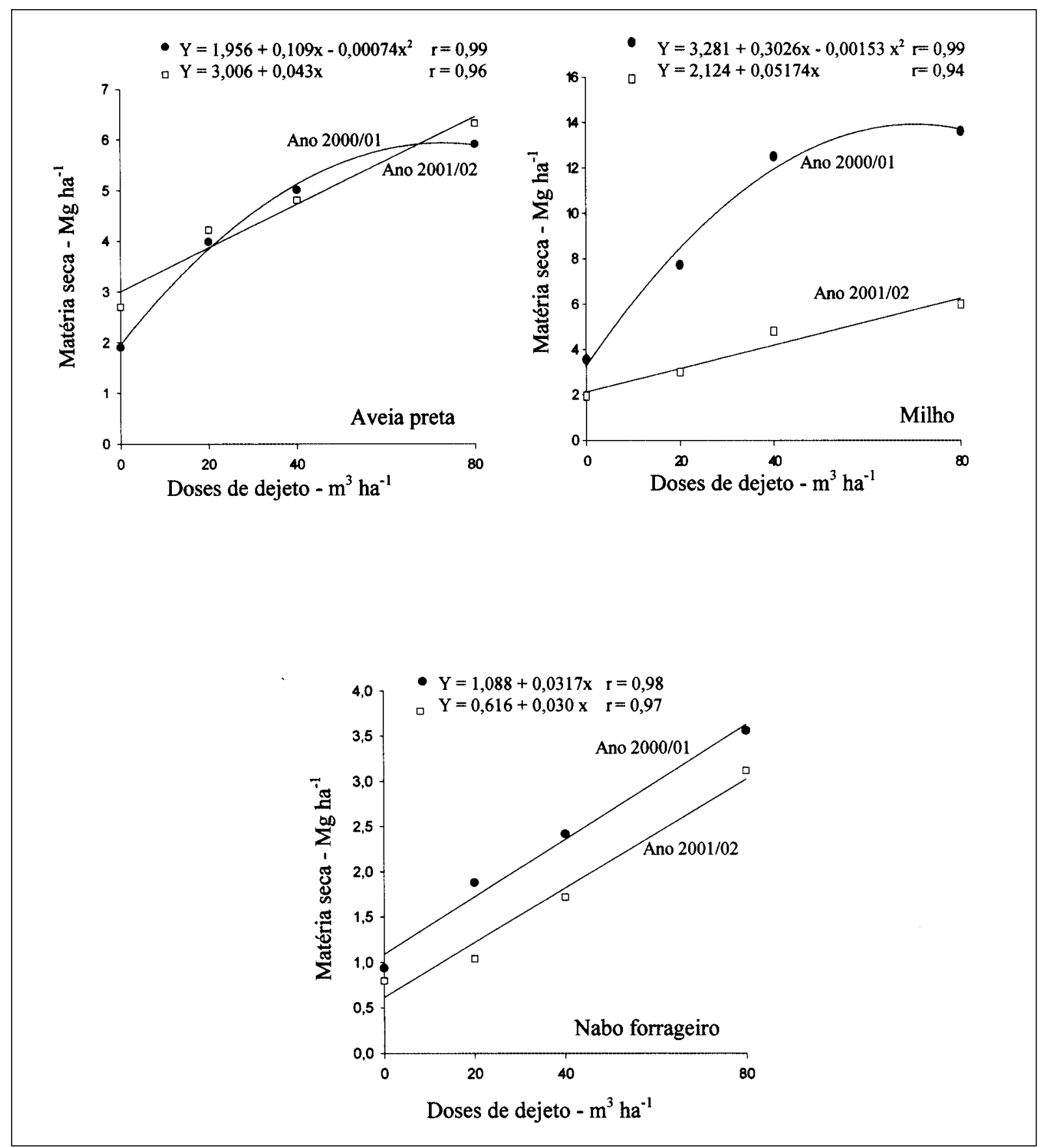

Figura 1 - Produção de matéria seca de aveia preta, milho e nabo forrageiro nos dois anos, com a utilização de três doses de dejeto líquido de suínos.

no segundo ano, que foram de 57, 114 e 229\%, em relação a testemunha para as doses de 20,40 e $80 \mathrm{~m}^{3}$ ha $^{-1}$, são maiores do que os porcentuais de acréscimo na produção de matéria seca, evidenciando o efeito residual no segundo ano da quantidade de $\mathrm{N}$ aplicada nas três aplicações de dejeto no primeiro ano. $\mathrm{Na}$ média dos dois anos e das seis aplicações, houve um aumento no acúmulo de $\mathrm{N}$ de 14,5, 10,2 e 7,4kg ha-1 para as doses de 20, 40 e $80 \mathrm{~m}^{3} \mathrm{ha}^{-1}$, respectivamente, mostrando que para cada $\mathrm{m}^{3}$ de dejeto utilizado nas doses de 20, 40 e $80 \mathrm{~m}^{3} \mathrm{ha}^{-1}$, os acúmulos de $\mathrm{N}$ foram de 2,41, 1,71 e 1,23kg ha ${ }^{-1}$, respectivamente. Levando-se em consideração a quantidade de $\mathrm{N}$ aplicada em cada dose nos dois anos, para cada $\mathrm{m}^{3}$ de dejeto aplicado o 

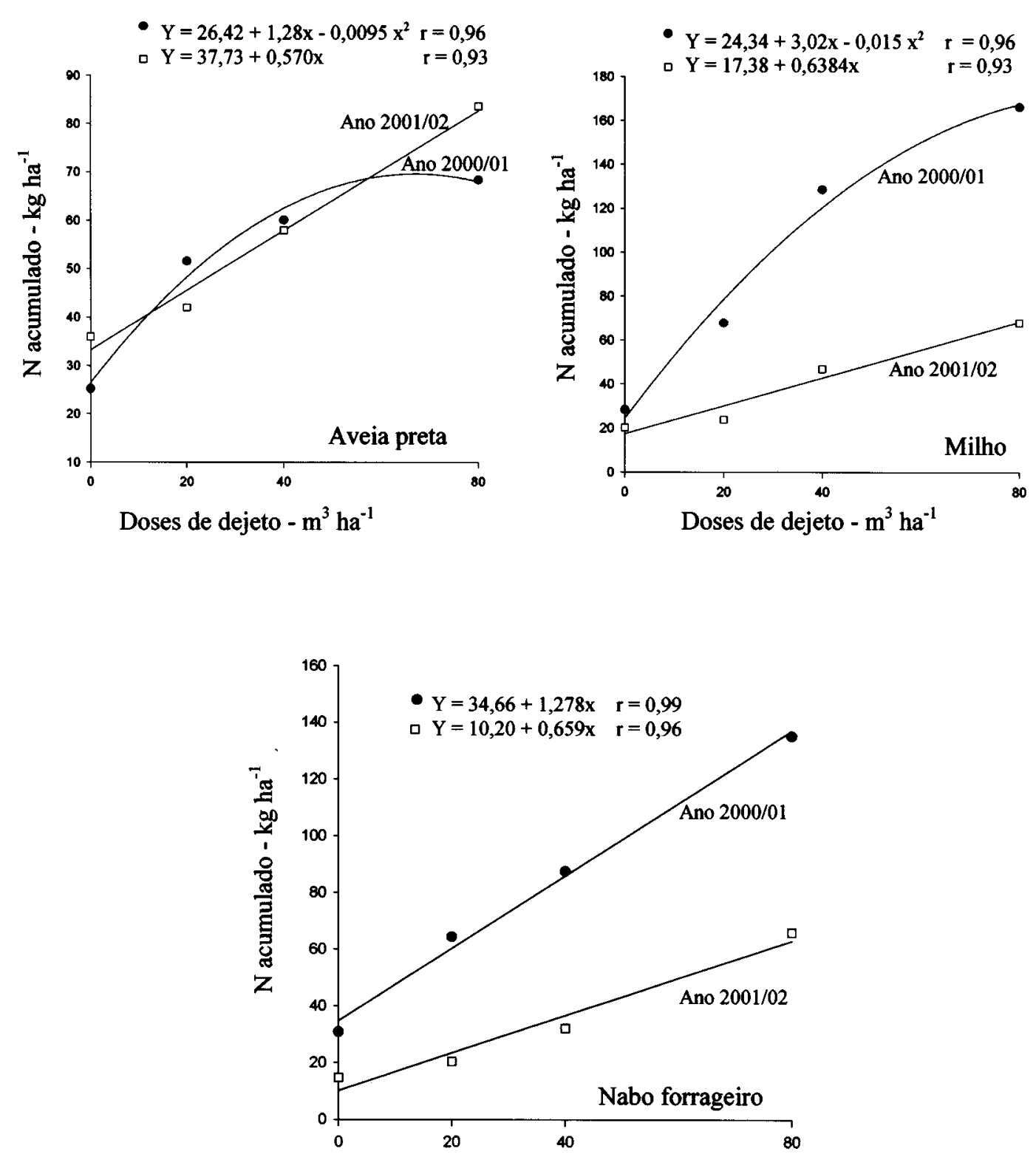

Figura 2 - Acúmulo de nitrogênio na parte aérea da aveia preta, milho, e nabo forrageiro nos dois anos, com a utilização de três doses de dejeto líquido de suínos.

acúmulo de $\mathrm{N}$ nas plantas foi de 1,01, 0,70 e 0,50 $\mathrm{kg} \mathrm{ha}^{-1}$. Todos esses dados evidenciam menor acúmulo de $\mathrm{N}$ nas plantas com o aumento nas doses de dejeto.

O acúmulo de fósforo e potássio na aveia preta e nabo forrageiro foi linear nos dois anos, apenas com exceção do potássio no primeiro ano de cultivo da aveia preta (Figura 3). Considerando os dois anos de cultivo de aveia preta o acúmulo de $\mathrm{P}$ na parte aérea foi de 35, 70 e $139 \%$ e o de K de 46, 81 e $117 \%$, em relação a testemunha, para as doses de 20, 40 e 80m ha $^{-1}$, respectivamente. Por outro lado, destaca-se o acúmulo de $\mathrm{P}$ e $\mathrm{K}$ no nabo forrageiro, pois atingiram porcentuais muito expressivos quando foi aplicado dejeto, sendo de 120, 239 e $478 \%$ o aumento no acúmulo de P e 130, 260 e 520\% no de K, em relação a testemunha, para as doses de 20, 40 e $80 \mathrm{~m}^{3}$ ha $^{-1}$, respectivamente, considerando os dois cultivos. Outro aspecto que reforça a habilidade do nabo forrageiro em acumular P e K, em relação a aveia preta, foi que nos dois anos o acúmulo de $\mathrm{P}$ na aveia preta atingiu 

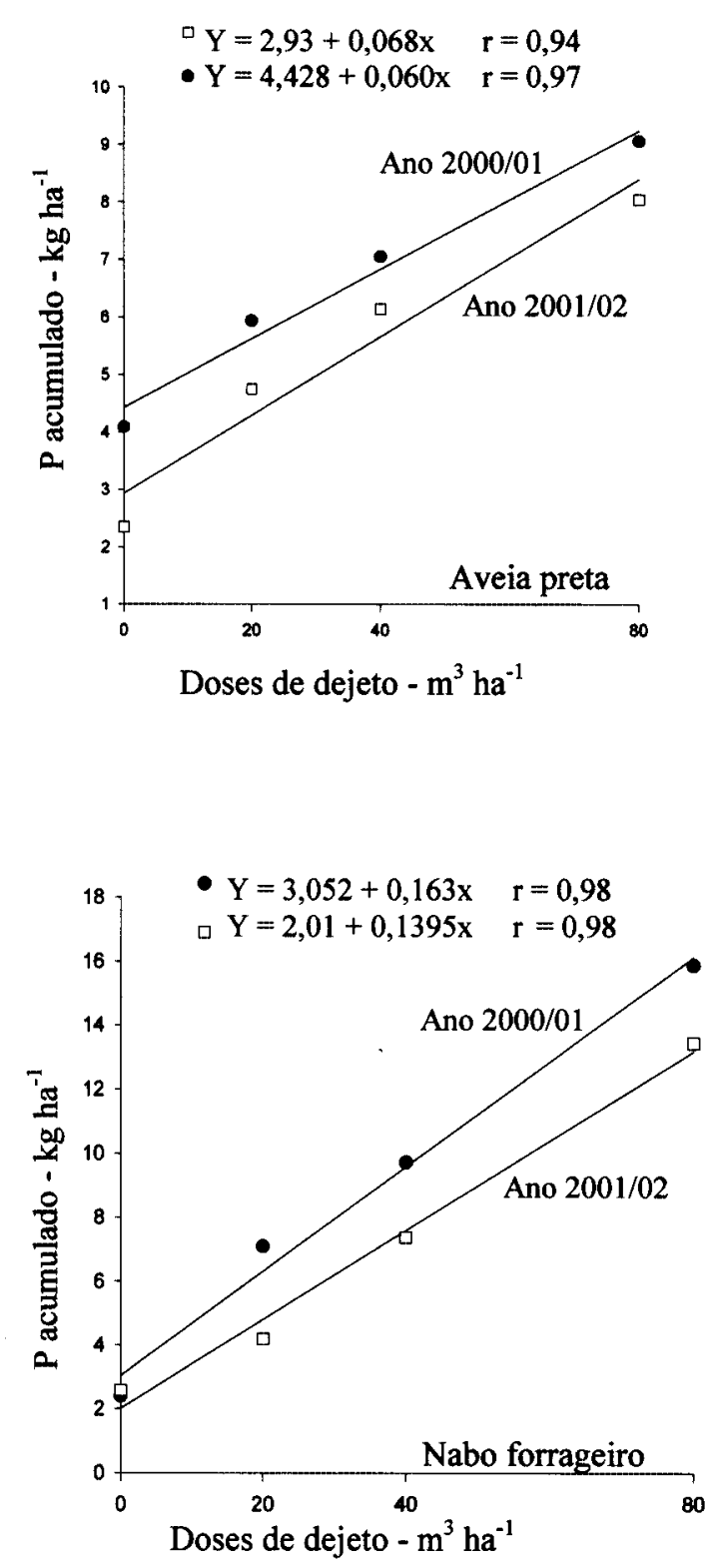
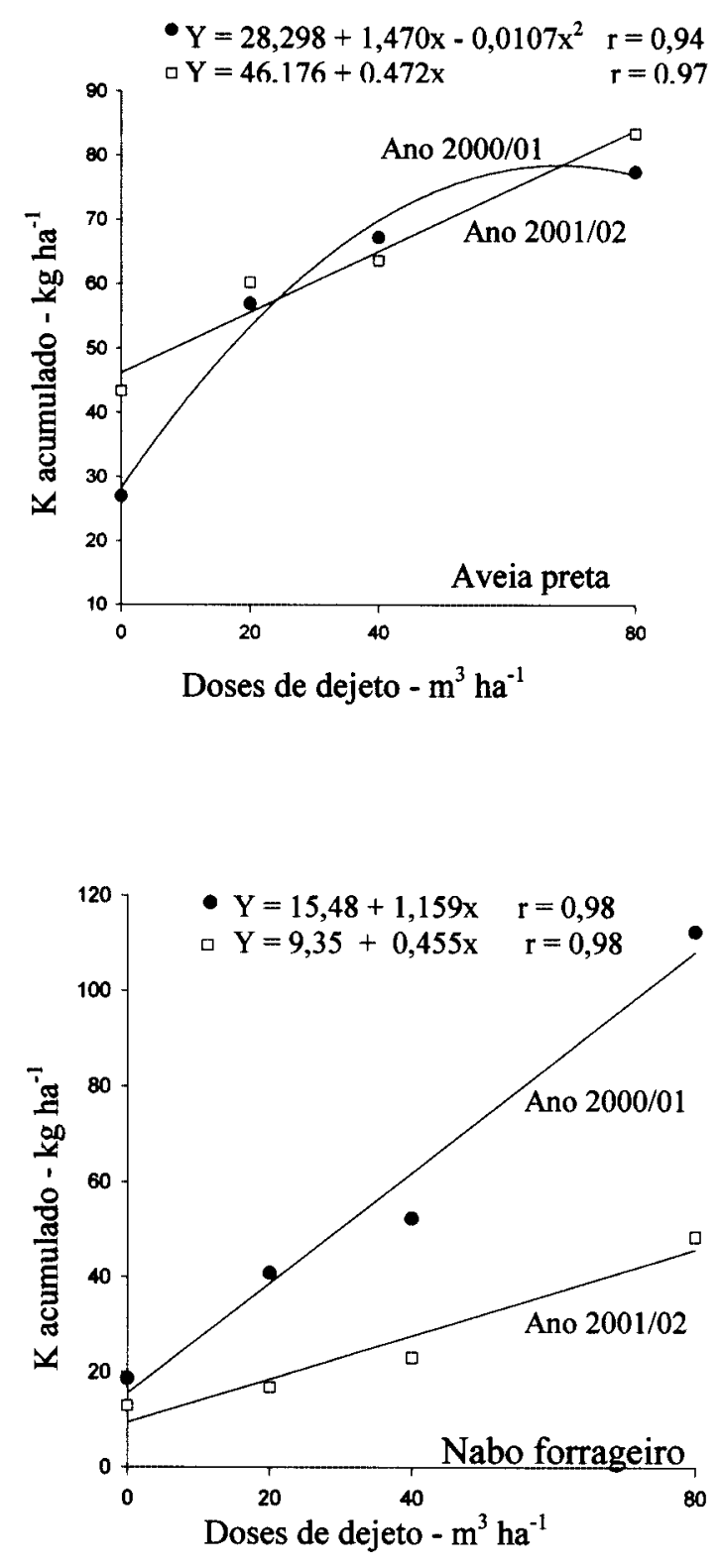

Figura 3 - Acúmulo de fósforo e potássio pela parte aérea da aveia preta e pelo nabo forrageiro, nos dois anos, com a utilização de três doses de dejeto líquido de suínos.

9,92, 12,48 e $17,60 \mathrm{~kg} \mathrm{ha}^{-1}$, enquanto que no nabo forrageiro, foi de $11,11,17,16$ e $29,26 \mathrm{~kg} \mathrm{ha}^{-1}$, para as doses de 20, 40 e $80 \mathrm{~m}^{3} \mathrm{ha}^{-1}$, respectivamente. Por sua vez, o acúmulo de K na aveia preta foi de 109,04, 135,04 e $161,36 \mathrm{~kg} \mathrm{ha}^{-1}$, enquanto que no nabo forrageiro foi de 57,11, 89,39 e 153,95kg ha-1, para as doses de 20, 40 e $80 \mathrm{~m}^{3} \mathrm{ha}^{-1}$, respectivamente.

Possivelmente as quantidades de $\mathrm{P}$ e $\mathrm{K}$ acumuladas nas camadas superficiais também tenham sido expressivas porque seus teores no solo eram altos, quando da instalação do experimento (CQFSRS/SC, 2004). Contudo, isso pode ser variável, porque com aplicação de 5,4t ha-1 de dejeto de suíno (base seca) em um Cambissolo de Santa Catarina ERNANI (1984), observou que a absorção de potássio pelas folhas de milho superou em $92 \%$ a testemunha sem aplicação de fertilizantes. Entretanto, ao trabalhar num Argissolo Vermelho distrófico arênico e com aplicação de $40 \mathrm{~m}^{3}$ ha ${ }^{-1}$ de dejeto líquido de suínos, BARCELLOS (1991) encontrou que a absorção de fósforo pela parte 
aérea do milho aumentou em 38\% com a utilização do dejeto, enquanto que, para o potássio, foi de apenas 6\%. Deve-se considerar que além das características químicas do solo, as diferenças na composição dos dejetos e as condições de clima resultam em variações nas respostas das culturas, tanto que se observa pelos dados da figura 3 e tabela 1 , que a menor absorção de P na aveia preta e no nabo forrageiro no segundo ano, também se justifica pela menor quantidade de $\mathrm{P}$ adicionada via dejeto.

A recuperação aparente de $\mathrm{N}, \mathrm{P}$ e K pelo milho foi de 28,7, 19,5 e 46,3\%, respectivamente, na média dos dois anos de cultivo e das três doses de dejeto aplicadas (Tabela 2). No primeiro ano, em média, as porcentagens de recuperação dos nutrientes foram menores, mesmo com produtividades muito superiores. Provavelmente isso se deve ao teor muito alto de matéria seca do dejeto aplicado, o que significou a adição de grandes quantidades de N, P e K via dejeto. Por outro lado, no segundo cultivo de milho o dejeto utilizado tinha baixo teor de matéria seca, ou seja, foram aplicados menos nutrientes e as plantas absorveram relativamente maiores quantidades desses, mesmo que a produtividade tenha sido inferior. Isso mostra como a recuperação pode variar e outro exemplo disso é o trabalho de RESS et al. (1993), no qual o aumento nas doses de dejeto resultou em incremento à absorção de $\mathrm{N}$ proveniente do dejeto, mas não à taxa de recuperação. Isso evidencia que o crescimento das plantas e sua produtividade, com o uso de dejetos, são conseqüências de mudanças favoráveis que ocorrem também na disponibilidade de outros nutrientes, em características físicas melhorando a estrutura do solo, e na atividade biológica.

Esses valores de recuperação de $\mathrm{N}$ estão bem abaixo dos $83 \%$ encontrados por PAUL \& BEAUCHAMP (1995), porém muito próximos aos obtidos por ALMEIDA (2000), quando o cálculo foi feito em cima da quantidade total aplicada. Vale lembrar, que essa alta recuperação aparente (83\%) do N aplicado via dejeto observado no trabalho de PAUL \& BEAUCHAMP (1995), foi estimada em cima da quantidade de $\mathrm{N}$ mineral aplicado via dejeto onde o mesmo foi uniformemente incorporado ao solo, que reduz a perda por volatilização, bem como pelo fato do experimento ter sido realizado em vaso e em casa de vegetação, onde o volume de solo explorado pelo

Tabela 2 - Recuperação aparente pelo milho, do nitrogênio, fósforo e potássio aplicados via dejetos nos dois anos.

\begin{tabular}{|c|c|c|c|c|c|c|}
\hline \multirow{3}{*}{$\begin{array}{l}\text { Doses de dejeto } \\
\mathrm{m}^{3} \mathrm{ha}^{-1}\end{array}$} & \multicolumn{2}{|c|}{ Quantidade aplicada } & \multicolumn{2}{|c|}{ Quantidade absorvida } & \multicolumn{2}{|c|}{ Recuperação aparente ${ }^{(1)}$} \\
\hline & \multicolumn{6}{|c|}{ Nitrogênio total } \\
\hline & $1^{\circ}$ ano & $2^{\circ}$ ano & $1^{\circ}$ ano & $2^{\circ}$ ano & $1^{\circ}$ ano & $2^{\circ}$ ano \\
\hline & \multicolumn{4}{|c|}{$\mathrm{kg} \mathrm{ha}^{-1}$} & \multicolumn{2}{|c|}{$\%$} \\
\hline 0 & - & - & 28,3 & 20,1 & - & - \\
\hline 20 & 151 & 40 & 60,3 & 33,8 & $21^{(2)}$ & 34 \\
\hline 40 & 301 & 80 & 128,6 & 47,0 & 33 & 33 \\
\hline \multirow[t]{4}{*}{80} & 602 & 160 & 162,7 & 68,0 & 22 & 29 \\
\hline & \multicolumn{6}{|c|}{ Fósforo total } \\
\hline & $1^{\circ}$ ano & $2^{\circ}$ ano & $1^{\mathrm{o}}$ ano & $2^{\circ}$ ano & $1^{\circ}$ ano & $2^{\circ}$ ano \\
\hline & \multicolumn{4}{|c|}{$\mathrm{kg} \mathrm{ha}^{-1}$} & \multicolumn{2}{|c|}{$\%$} \\
\hline 0 & - & - & 3,3 & 1,5 & - & - \\
\hline 20 & 42 & 12 & 5,2 & 3,5 & 4,5 & 16,7 \\
\hline 40 & 84 & 24 & 8,9 & 4,8 & 6,7 & 13,7 \\
\hline \multirow[t]{4}{*}{80} & 168 & 48 & 11,9 & 6,4 & 5,1 & 10,2 \\
\hline & \multicolumn{6}{|c|}{ Potássio total } \\
\hline & $1^{\circ}$ ano & $2^{\circ}$ ano & $1^{\circ}$ ano & $2^{\circ}$ ano & $1^{\circ}$ ano & $2^{\circ}$ ano \\
\hline & \multicolumn{4}{|c|}{$\mathrm{kg} \mathrm{ha}^{-1}$} & \multicolumn{2}{|c|}{$\%$} \\
\hline 0 & - & - & 34,4 & 33,3 & - & - \\
\hline 20 & 91 & 16 & 67,8 & 38,1 & 37 & 30 \\
\hline 40 & 183 & 32 & 103,3 & 58,2 & 38 & 77 \\
\hline 80 & 365 & 64 & 149,1 & 75,6 & 31 & 65 \\
\hline
\end{tabular}

\footnotetext{
${ }^{(1)}$ Recuperação aparente do N, P e K do dejeto pelo milho = absorvido nas respectivas doses - absorvido na testemunha total adicionado via dejeto

(2) Observar que no cálculo foi descontado o valor das perdas na testemunha.
} 
sistema radicular é menor e não ocorre perdas por percolação.

O fósforo foi o que apresentou o menor porcentual de recuperação, o que pode ser justificado pela menor quantidade exigida pela cultura e pelo fato de que a maior parte do $\mathrm{P}$ do dejeto faz parte de compostos orgânicos, não estando prontamente disponível às plantas. Os menores porcentuais de recuperação de $\mathrm{P}$, aliado à sua muito baixa mobilidade no solo, mostram o potencial de acúmulo de P no solo, especialmente em camadas superficiais (CERETTA et al., 2003), o que pode significar contaminação do ambiente por eutroficação. Por isso o acúmulo de $\mathrm{P}$ no solo com o uso de dejetos deve ser monitorado, especialmente em sistemas sem revolvimento de solo. Por sua vez, o K foi o que apresentou a maior recuperação aparente, o que pode ser devido a grande demanda das plantas e ao fato de que quase todo o $\mathrm{K}$ do dejeto estar em forma prontamente disponível às plantas. Observa-se que, em muitos casos, a maior recuperação dos nutrientes aplicados via dejeto ocorreu com o uso de $40 \mathrm{~m}^{3} \mathrm{ha}^{-1}$, independentemente para $\mathrm{N}, \mathrm{P}$ e $\mathrm{K}$, sugerindo que esta dose, nestas circunstâncias, poderia ser um referencial prático a ser considerado para uso.

A produtividade de grãos de milho, nos dois anos aumentou com o uso de dejeto (Figura 4), sendo que a máxima eficiência técnica foi atingida com $85 \mathrm{~m}^{3}$ ha $^{-1}$ de dejeto no primeiro ano, ou seja, muito similar aos $86 \mathrm{~m}^{3}$ ha $^{-1}$ que foi para a produção de matéria seca (Figura 1). No segundo ano, a produtividade foi linear com as doses de dejeto. A maior produtividade no primeiro ano deve-se principalmente ao alto teor de matéria seca do dejeto aplicado. Além disso, como não houve mudança de local da área experimento, no segundo ano de cultivo do milho toda a área experimental já tinha sido utilizada com dois cultivos de aveia preta e um cultivo de milho, o que pode ter provocado a imobilização de parte do $\mathrm{N}$ aplicado via dejeto, devido a alta relação $\mathrm{C} / \mathrm{N}$ da palhada. No segundo ano, mesmo com aplicação de $160 \mathrm{~kg}$ de $\mathrm{N}$ ha $^{-1}$ na dose de $80 \mathrm{~m}^{3} \mathrm{ha}^{-1}$, as plantas de milho mostraram sintomas visuais de deficiência de N. Por isso que os porcentuais de aumento na produtividade de grãos foram de 292, 585 e 1171\% em relação a testemunha, para as doses de 20,40 e $80 \mathrm{~m}^{3} \mathrm{ha}^{-1}$, respectivamente, no segundo ano, contra 193, 317 e 439\% no primeiro ano. Em função disso, a produtividade de grãos por $\mathrm{m}^{3}$ de dejeto foi de 408 , 291 e $188 \mathrm{~kg} \mathrm{ha}^{-1}$ no primeiro ano e de 100,87 e $81 \mathrm{~kg}$ ha $^{-1}$ no segundo ano, para as doses de 20,40 e $80 \mathrm{~m}^{3}$ $\mathrm{ha}^{-1}$, respectivamente, evidenciando que as respostas às doses podem ser variáveis uma vez que não existe controle sobre a qualidade do dejeto, bem como as condições de solo, clima e manejo podem variar influenciando na resposta às doses de dejeto. Por isso que os dados deste trabalho não evidenciaram claramente uma dose que tenha se destacado e que pudesse ser citada como um referencial para uso prático, pois falta a análise econômica e as considerações sobre o impacto ambiental. Entretanto, SCHERER et al. (1986) concluíram que a dose $40 \mathrm{~m}^{3}$ ha $^{-1}$ de dejeto de suínos foi a melhor dose sob o ponto de vista técnico e econômico para a produtividade de grãos de milho no Oeste Catarinense.

\section{CONCLUSÕES}

A maior eficiência técnica para a produtividade de grãos de milho e para produção de matéria seca de aveia preta ocorreu com doses muito altas de dejeto líquido de suínos, ou seja, em torno de $85 \mathrm{~m}^{3} \mathrm{ha}^{-1}$, que somado ao incremento linear no acúmulo de N, P e K, na maioria dos casos, evidencia que na tomada de decisão sobre doses de dejeto devem ser levados em consideração também aspectos operacionais, econômicos e ambientais. O nabo forrageiro foi a cultura que se destacou na ciclagem dos nutrientes aplicados via dejeto líquido de suínos. Os porcentuais de recuperação aparente de nutrientes pelo milho, que foram na ordem $K>N>P$, mostram que devem ser tomadas medidas para a conservação do solo visando maior aproveitamento do efeito residual, diminuindo o potencial de perdas.

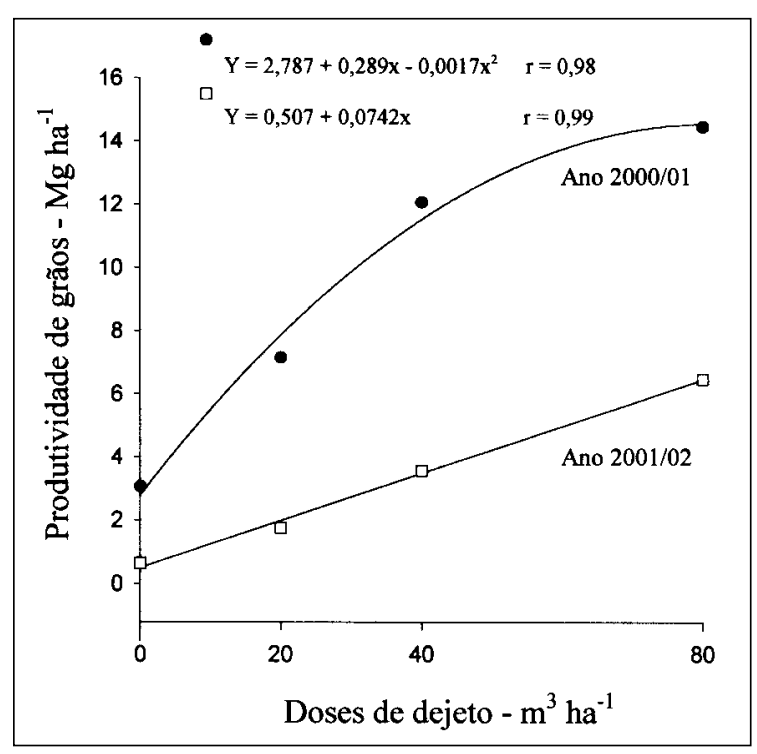

Figura 4 - Produtividade de grãos de milho com aplicação de dejeto líquido de suínos em dois anos agrícolas.

Ciência Rural, v.35, n.6, nov-dez, 2005. 


\section{AGRADECIMENTOS}

Ceretta, bolsista do Conselho Nacional de Desenvolvimento Científico e Tecnológico (CNPq). Trentin e Girotto, bolsistas Iniciação Científica.

\section{REFERÊNCIAS}

ALMEIDA, A.C.R. Uso associado de dejeto líquido de suínos e plantas de cobertura de solo na cultura do milho. 2000. 114f. Dissertação (Mestrado em Agronomia) - Programa de Pós-graduação em Agronomia, Universidade Federal de Santa Maria.

BARCELLOS, L.A.R. Avaliação do potencial fertilizante do dejeto líquido de suínos de bovinos. 1991. $108 \mathrm{f}$. (Mestrado em Agronomia) - Programa de Pós-graduação em Agronomia, Universidade Federal de Santa Maria.

COMISSÃO DE QUIMICA E FERTILIDADE DO SOLO (CQFS RS/SC). Manual de adubação e de calagem para os estados do Rio Grande do Sul e Santa Catarina. 10.ed. Porto Alegre: Sociedade Brasileira de Ciência do Solo/ Núcleo Regional Sul, 2004. 400p.

CERETTA, C.A. et al. Características químicas de solo sob aplicação de dejeto líquido de suínos em pastagem natural. Pesquisa Agropecuária Brasileira, Brasília, v.38, n.6, p.729-735, 2003.

DURIGON, R. et al. Produção de forragem em pastagem natural com o uso de esterco líquido de suínos. Revista Brasileira de Ciência do Solo, Viçosa, v.26, n.4, p.983-992, 2003.

ERNANI, P.R. Necessidade da adição de nitrogênio para o milho em solo fertilizado com dejeto líquido de suínos, cama de aves e adubos minerais. Revista Brasileira de Ciência do Solo, Viçosa, v.7, n.8, p.313-317, 1984.

EVANS, S.D. et al. Effects of solid and liquid beef manure and liquid hog manure on soil characteristics and on growth, yield and decomposition of corn. Journal Environmental Quality, v.6, p.361-368, 1977.

FAUVEL, Y.; MORVAN, T. Management of pig slurry for nitrogen fertilization of corn. Contribution au colloque Ramiran 98. Rennes, 26-28 mai 1998.

PAUL, J.W.; BEAUCHAMP, E.G. Availability of manure slurry ammonium for corn using ${ }^{15} \mathrm{~N}$-labelled $\left(\mathrm{NH}_{4}\right)_{2} \mathrm{SO}_{4}$. Canadian Journal of Soil Science, v.77, p.35-42, 1995.

RESS, R.M. et al. The release and plant uptake of nitrogen from some plant and animal manures. Biology and Fertility of Soil, v.15, p.285-293, 1993.

SCHERER, E.E. et al. Utilização de dejeto líquido de suíno como fonte de $\mathbf{N}$ para as culturas de milho e feijão. Florianópolis: EMPASC, 1986. 4p. (Pesquisa em andamento, 56).

SCHERER, E.E. et al. Avaliação da qualidade do dejeto líquido de suínos da região Oeste Catarinense para fins de utilização como fertilizante. Florianópolis: EPAGRI, 1996. 46p. (Boletim técnico).

SCHMITT, D.R. Avaliação técnica e econômica da distribuição de dejeto líquido de suínos. Santa Maria. 1995. 151f. Dissertação (Mestrado em Engenharia Agrícola) - Programa de Pós-graduação em Engenharia Agrícola, Universidade Federal de Santa Maria.

TEDESCO, M.J. et al. Análise de solo, plantas e outros materiais. Porto Alegre: Departamento de Solos, UFRGS, 1995. 174p.

ZEBARTH, R.J. et al. Influence of the time and rate of liquid manure application on yield and nitrogen utilization of silage corn on south coastal British columbia. Canadian Journal of Soil Science, v.76. p.153-164, 1996. 